
\title{
(s)
}

\section{Methodologies of Application of Sol-Gel Based Solution onto Substrate: A Review}

\author{
Saheli Bera ${ }^{1}$, G. Udayabhanu ${ }^{1}$, Ramanuj Narayan ${ }^{2}$ and Tapan K. Rout ${ }^{3, *}$ \\ ${ }^{1}$ Applied Chemistry Department, Indian School of Mines University, India \\ ${ }^{2}$ Organic Coatings Department, CSIR-Indian Institute of Chemical Technology, India \\ ${ }^{3}$ Reserach \& Development Department, Tata Steel Ltd., India
}

\begin{abstract}
Just as the diverse as the various substrates that can be coated is the choice of several coating methods by which the coating can be applied to these pretreated surfaces. They include the manual methods, where great skills and experience is needed, on the other hand there are automated and robotics coating control methods where coating can be applied with more precise manner. Sol-gel process is one of the promising bottom up nano-coating technologies to develop thin film over various metallic substrates. The property and characteristic of the resulting film is strongly influenced by the various parameters and reaction conditions of the sol-gel process and of course on the deposition techniques. In this review, we have thrown some lights on different coating application processes covering theoretical principle, advantages, disadvantages, and special various parameters controlling the final film quality.
\end{abstract}

Received on 20-10-2015 Accepted on 08-12-2015 Published on 24-05-2016

Keywords: Sol gel, coatings, application methods, thin film, process parameters

\section{INTRODUCTION}

In recent time sol-gel process is being considered as one of the simplest technique to develop thin films, which can offer almost any single- and multi- component oxide coating on metal and glass [1, 2]. Sol-gel derived coating can be employed in electronics, optical, magnetic or coating having chemical functions [3]. Sol-gel derived ceramic film are now being extensively used for protection from corrosion and oxidation of stainless steel, aluminum, copper, zinc, and magnesium substrates [4]. A huge acceleration in the development of coating in the recent years is due to the availability of different coating methods, which can control the critical properties of the resulting thin film such as morphology, adhesion, barrier property, composition, structure etc. [5]. A solid material is said to be in thin film form when it is grown on the surface of a solid substrate by controlled condensation of the individual atomic, molecular or ionic species. There are several dozens of techniques are available for thin film deposition for forming the layer in the thickness region of a few Nano meter to approximately ten micrometers. But the classification of different deposition technique can be simplified by limiting the number of techniques to be considered [6]. The two most important and

"Reserach \& Development Department, Tata Steel Ltd., India; Tel: 91-6576648885, 91-8092088390; E-mail: tkrout5@yahoo.com traditional techniques are physical vapor deposition (PVD) and chemical vapor deposition (CVD). The PVD process normally uses inorganic elements or compounds or gases. Whereas, CVD process, spin coating, dip coating processes use liquid inorganic compounds, organic compounds and gases. The liquid compounds and gaseous compounds are directly purchased from the suppliers because in these cases no special preparation scheme is required. But the solid compounds must be compact and in suitable shape, free from any kind of gas inclusion and often have to be prepared according to a specific recipe. Moreover target must also have some specific structural characteristics such as appropriate grain size and texture [7]. In the following section different useful and important aspects of individual technique have been outlined, starting from simple manual techniques like brushing, rolling, widely used dip coating, spin coating, flow coating and finally highly sophisticated techniques like CVD and spray coating.

\section{MANUAL COATING METHOD}

\subsection{Brushing}

Application of coating with the help of a brush is as necessary as ever for small parts, for retouching the surface. The material and shape of the brush should be chosen according to coating material and the object. Thus flat brushes are 
useful for low viscosity strippers and paints, whereas round brushes are more suitable for more viscous coating or paints, e.g. pigmented coatings. Different brush materials should be used for waterborne and solvent borne coatings.

The advantage of brushing are i) it can be used for any shape of subject, ii) good wetting and covering of surface defects, iii) low coating losses.

The disadvantages and limitations of brushing are i) laborintensive, ii) flow of coating is difficult and risks of brush marks, iii) uniform coating thickness is difficult to achieve [8].

\subsection{Rolling}

As with brushing, in rolling too the choice of the tool should be made according to coating material. The advantages are i) rolling is much less labor intensive, ii) the film thickness is more uniform as compared to brushing, iii) very smooth surface can be achieved as no brush marks are left.

The disadvantages related to rolling process are i) the substrate surface should be even, ii) wetting of substrate is not as good as with brushing and iii) rapid rolling may cause spattering of coating [8].

\section{SPIN COATING}

\subsection{Spin Coating Process Theory and Description}

Spin coating is being widely used for several past decades for the application of thin film having a thickness in the range of micrometers to nanometers $[9,10]$. A typical spin process consists of a step in which the coating fluid is deposited onto the substrate surface, a high speed spin process for thinning the fluid and a drying step to evaporate the excess solvent from the final thin film [9]. In most of the cases coating material is polymeric and is applied in the form of a solution [11].

Generally two methods of spin coatings are commonly used, static dispense method and dynamic dispense method. In static dispense method a small puddle of fluid is deposited on the center of the substrate. This can range from 1 to $10 \mathrm{cc}$ depending on the fluid viscosity and the substrate size to be coated. A larger puddle is required for higher viscosity and larger substrate to ensure full coverage of the substrate during high spin speed. In the case of dynamic dispense, the substrate rotates at a low speed and the resin is dispensed on it. In this process a speed of about $500 \mathrm{rpm}$ is commonly used. After this dispense step the spinning substrate is accelerated to higher spin speed to thin the fluid and to achieve desired film thickness. The spin speed in this step generally lies in the range of $1500-6000 \mathrm{rpm}$. A separate drying step is often required after high speed spin step to further dry the film without thinning it. This can be especially advantageous for thick film, as long drying period may be necessary to stabilize the film before handling $[9,10,12,13]$. Sequential steps are mentioned in Figure 1.

\subsection{Important Factors Controlling the Final Film Properties}

\subsubsection{Spin Speed}

Spin speed is one of the most important factors in spin coating process. The centrifugal force applied to the liquid coating and the characteristics turbulence of the air immediately above the substrate is affected remarkably by the speed of the substrate. The final film thickness is defined by the high speed spin step. Minor variation of spin speed by approximately $50 \mathrm{rpm}$ at this stage can cause $10 \%$ change in resulting film thickness. The final film thickness is a result of a balance between the force applied to shear the fluid towards the edge of the substrate and the drying rate $[9,14,15]$.

\subsubsection{Spin Acceleration}

The acceleration towards the final spin speed influences the coated film properties. Since the resin begins to dry during the first part of the spin cycle, hence it is very essential to control the acceleration. In most cases, $50 \%$ of the solvent evaporates out from sol in the first few seconds of the process.

Acceleration also plays an important role in the coating properties of the patterned substrates. In many cases topographical features are retained from the previous processes. Hence it is always advised to coat the resin uniformly and through these features. While the spin speed offers an outward radial force to the coating, the acceleration provides a twisting force to the resin. This twisting force allows dispersal of the resin around the topography [9].

\subsubsection{Drying}

In the course of the spin process the drying rate of the coating fluid is pre-decided by the nature of the fluid and the volatility of the solvent used. However the drying rate also depends on surrounding temperature of the substrate. It is clearly known that, the factors such as air temperature and humidity determine the coated film properties. However, it is very important that the airflow and associated turbulence above the substrate should be strictly minimized or held constant.

Slower rate of drying causes increased film thickness and uniform coverage across the substrate surface. In spin process, the fluid gradually dries out as it moves towards the edge. As a consequence the viscosity of the coating fluid changes from the center towards the edge of the substrate. Hence, a non-uniformity in film thickness also occurs with change in viscosity from the center towards the edge. However, by slowing down the rate of drying it is possible to achieve more or less a constant viscosity across the substrate surface.

Drying rate and final film thickness is also dependent on ambient humidity. A small change in humidity in the surrounding atmosphere can lead to a significant change in 
film thickness. To avoid this difficulty, recently many spin coater system is associated with a "closed bowl" facility providing an airtight environment. If the spinning is carried out in a closed bowl system, the solvent vapor is retained in the bowl and most of the problems due to humidity variation in atmosphere can be eliminated. Hazardous effects due to air flow around the spinning substrate can also be avoided by this closed bowl method. Various factors such as turbulence and eddy currents are generated from this air flow. Drastic alteration in downward flow of air can be created by minor changes in environment. If the bowl is closed with a smooth lid, then all these disturbing factors can be eliminated [9].
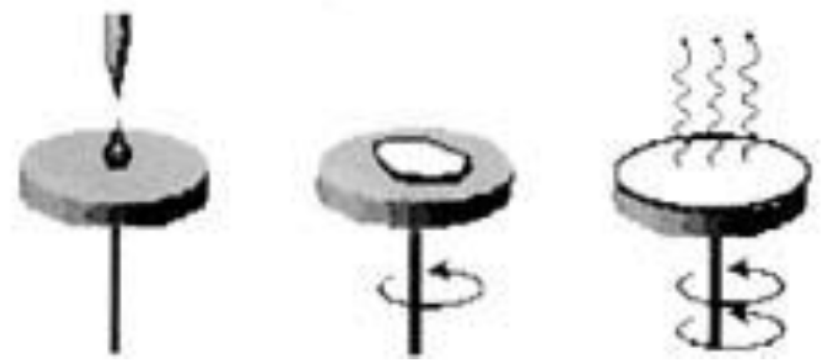

Figure 1: Sequential steps in a spin coating process [17].

\subsection{Graphical Presentation of Film Thickness vs. Different Process Parameters}

The following graphs are shown in Figure 2 represent the trend of variation of film properties with various process parameters. In Figure 2a the trend of variation of film thickness with spin time and spin speed has been shown
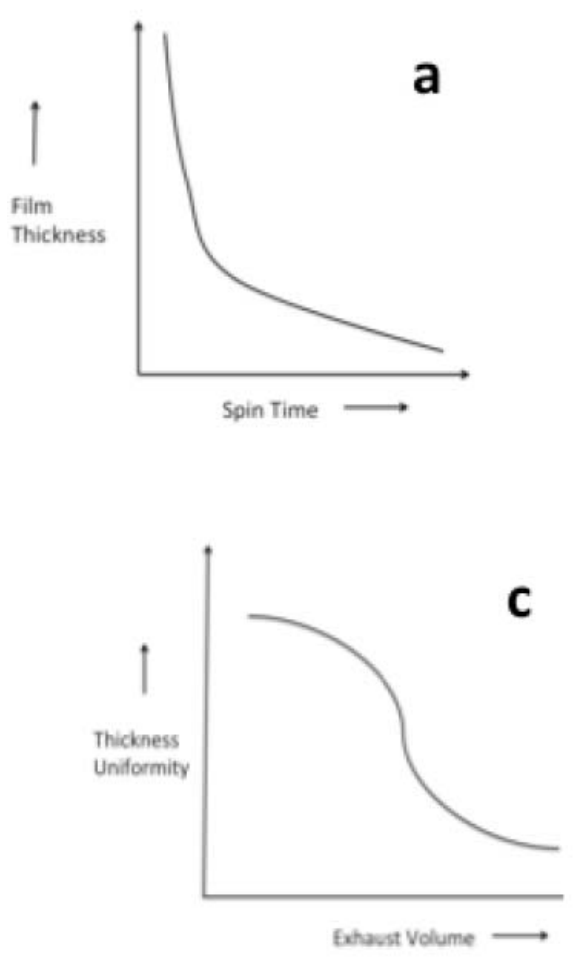

respectively whereas in Figures $\mathbf{2 b}, \mathbf{2} \mathbf{c}$ represent the variation of thickness uniformity and Figure $\mathbf{2 d}$ film thickness with exhaust volume respectively. In most of the cases the film thickness is inversely proportional to spin speed and spin time. Moreover, the final film thickness and film uniformity is somewhat dependent on the exhaust volume. However the effect of these parameters vary remarkably for different coating materials and substrates. There are no any hard and fast rules for this process, but most common observations have been mentioned as general guideline [9].

\subsection{Some Common Problems in Spin Coating Method and Their Solutions}

Here some common difficulties that often arise during a spin coating process have been mentioned. The probable reason and the possible solutions have been given in tabular form [9].

\subsection{Advantage and Disadvantage}

Spin coating has several advantages in coating operations. The most important point is to get thin film at a controllable coating solution rheology and by tuning the spin speed. One can obtain progressively more uniform film thickness by using this technique. Another point is equally important for the industry where this technique is a kind of fast operating system at a reasonable cost.

Spin coating technique has few disadvantages but they are becoming more and more important as the substrate size increases. Large substrates cannot be spun at a sufficient
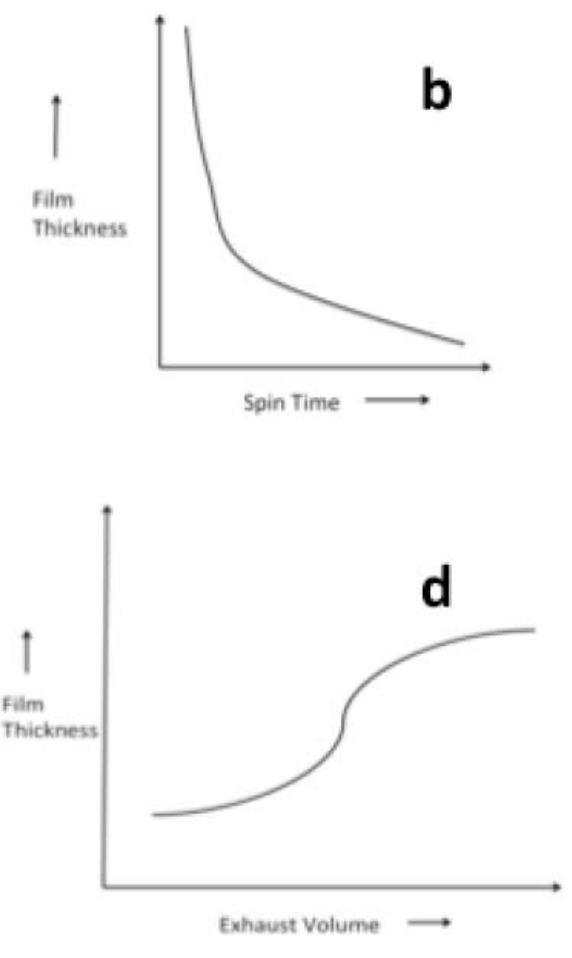

Figure 2: (a) Film thickness with spin time, (b) Film thickness with spin speed, (c) Film thickness uniformity with exhaust volume \& (d) Film thickness with exhaust volume. 
Table 1: Reasons and Solutions for too Thin Final Film

\begin{tabular}{|c|c|}
\hline Probable Reason & Method to Overcome \\
\hline \hline Spin speed is too high & Lower speed should be selected \\
\hline Spin time is too long & Decrease high speed spinning time \\
\hline Inappropriate choice of resin with very low viscosity & A resin with suitable viscosity should be selected \\
\hline
\end{tabular}

Table 2: $\quad$ Reasons and Solutions for too Thick Final Film

\begin{tabular}{|c|c|}
\hline Probable Reason & Method to Overcome \\
\hline \hline Spin speed is too low & Higher spin speed should be selected \\
\hline Spin time is too short & Time duration of high speed spin should be increased \\
\hline Exhaust volume is too high & Exhaust volume should be adjusted \\
\hline Viscosity of the resin is very high & Resin with lower viscosity should be chosen \\
\hline
\end{tabular}

Table 3: Reasons and Solutions for Appearance of Pinholes in the Final Film

\begin{tabular}{|c|c|}
\hline Probable Reason & Method to Overcome \\
\hline \hline Air bubbles in dispense fluid & Bubbles should be eliminated by slight heating or substitution by inert gas or centrifuge \\
\hline Particles in fluid & Particles should be carefully removed from fluid \\
\hline Particle exist on substrate surface prior to dispense & Proper surface preparation prior to dispense so that the surface is free from any foreign particles \\
\hline
\end{tabular}

Table 4: Reasons and Solutions for Poor Reproducibility

\begin{tabular}{|c|c|}
\hline Probable Reason & Method to Overcome \\
\hline \hline Variable exhaust condition & Exhaust lid should be adjusted and fully closed \\
\hline Substrate is not loaded properly & Substrate should be placed properly before operation \\
\hline Dispense volume is not sufficient & Dispense volume should be increased \\
\hline Balance between time and speed parameter is not stable & Increase speed/decrease time or vice versa \\
\hline
\end{tabular}

Table 5: Reasons and Solutions for Poor Quality Final Film

\begin{tabular}{|c|c|}
\hline Probable Reason & Method to Overcome \\
\hline Exhaust volume is too high & Exhaust lid should be adjusted \\
\hline Insufficient dispense volume & Dispense volume should be increased \\
\hline Balance between time and speed parameter is not stable & Increase speed/decrease time or vice versa \\
\hline Acceleration is too high & Lower acceleration should be selected \\
\hline Inappropriate choice of coating & Coating with good quality should be used \\
\hline
\end{tabular}

spin, hence the film thinning procedure is difficult to achieve. Material utilization is low in this process, only 2 to $5 \%$ coating is dispersed on the substrate, whereas, the remaining portion is flung off into the bowl and disposed.

\section{DIP COATING METHOD}

The sol-gel dip coating technique simply consists of immersion of a substrate into the fluid sol and then withdrawing the substrate from the sol with a well- defined velocity under controlled condition of temperature and pressure [16]. After the withdrawal step, the solvent is evaporated accompanied by further condensation reaction, resulting in the deposition of the solid film [18] as shown in Figure 3. Dip coating method can be considered as a more advantageous method for thin film deposition than the conventional methods like chemical vapor deposition, evaporation or sputtering, as it requires considerably less 
equipment and is less expensive. In this section the fundamental physics and chemistry of dip coating method has been reviewed.

\subsection{Physics and Chemistry of Dip Coating Technique}

The thickness of the final film is strongly dependent on i) withdrawal velocity, ii) viscosity of the coating fluid and iii) solid content of the liquid. There are six forces that act on the coating simultaneously during withdrawing, 1) the moving substrate imparts an upward viscous drag on the liquid, 2) force of gravity, 3) resultant force of surface tension in a concavely shaped meniscus, 4 ) inertial force of the boundary layer liquid present at the deposition region, 5) disjoining or conjoining pressure (specially important for films having thickness less than $1 \mathrm{~nm}$ ) and finally 6) surface tension gradient $[18,19,20]$.

\subsubsection{Thin Film Equation and Boundary Condition}

Let us assume, the flow of an incompressible fluid of density $\rho$, viscosity $\mu$ and surface tension $\sigma$, which is entrained by the flat plate when it is moved vertically upward with a velocity UO from the infinite bath solution, in $(X, Y)$ plane. The gravitational force acts in the downward direction. As a consequence of this withdrawal the thin film is divided into three separate regions. The region close to the fluid bath is considered to be static and mentioned as static meniscus region. As the fluid is entrained by the moving plate, it can not exist in the static phase. However, near fluid bath surface, the surface tension becomes dominant over the viscous force. As a result it resists the liquid to flow. On the contrary, the surface tension effect remains inactive far above from the fluid bath surface. Therefore, when the film reaches the region far above the liquid bath, free surface of the film is in a parallel plane with the plate movement. Since the film thickness in this region remains constant, it is called constant thickness region. In between these two regions, there is a dynamic region where developing flow condition exists [21].

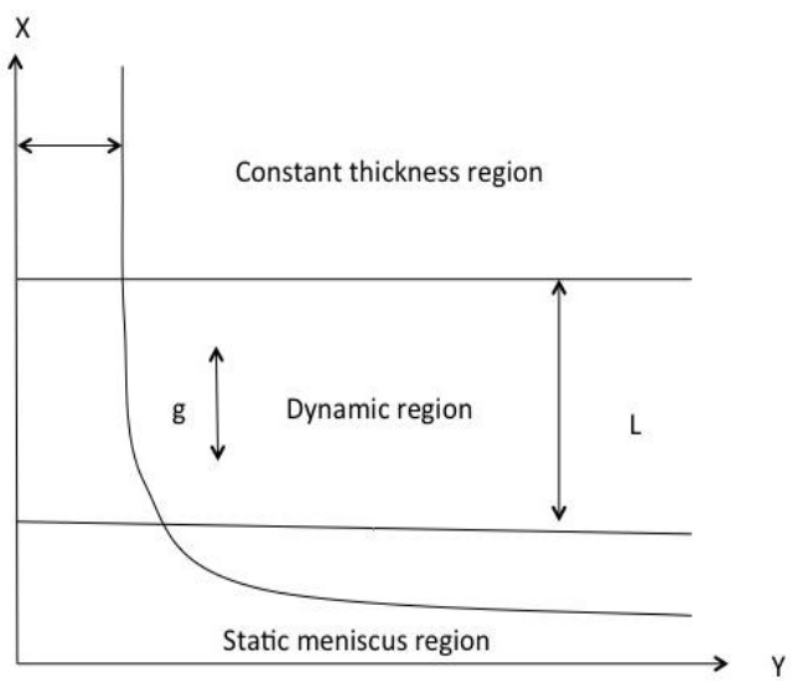

Figure 3: Schematic illustration of three separate regions in the thin film due to the vertical withdrawal of substrate from coating bath [21].
When the liquid viscosity $\eta$ and the substrate speed $U 0$ are high enough to lower the curvature of the meniscus, the deposited film thickness $h$ balances the viscous drag and gravity force.

$h=c 1(\eta U 0 / \rho g)^{1 / 2}$

as viscous drag is proportional to $(\eta U 0 / h)$

where $c_{1}$ is a constant having a numerical value about 0.8 for the Newtonian fluid. When the substrate speed and viscosity are, often observed in the case of sol-gel coating, the balance is adjusted by the ratio of viscous drag to liquid vapor surface tension $\gamma_{L, V}$ following the relationship derived by Landau and Levich [21, 22].

$h=0.94(\eta U 0)^{2 / 3} /(\gamma L, V)^{2 / 3}(\rho g)^{1 / 2}$

\subsection{Effect of Substrate Speed}

From equation (1) \& (2) it is evident that an increase in the film thickness occurs with the increase in substrate speed $U_{0}$. Naturally thicker film will take a longer time to dry as most of the solvent evaporation occurs from the exterior surface of the entrained sol. This leads to a higher aging period. A second effect of the substrate speed is the shear effect induced on a particle within the depositing sol. When the shear effect experienced by a sol particle is greater than its deposition coefficient, the mutually repulsive particles will be oriented in closed packed plane parallel to the substrate surface.

The withdrawal speed can affect the film structure in another way, increased withdrawal speed results in increase in thickness of the resulting film, which leads to increased drying time. As a finite time is required for the alignment and orientation of the repulsive particle in crystal like structure, so the ordering of the repulsive particle can be achieved by increasing the drying time. On the other hand, in case of reactive sols increased drying time is one of the reasons of increased stiffening of the silicate structure, prior to final drying of the film. This results in generation of more porous film. Hence to control the porosity of the final film the coating rate should be tuned properly.

\subsection{Effect of Viscosity of Liquid}

In the process of dip coating when the substrate is dipped into coating and it is pulled out, the excess coating is drained off the object and solvent is evaporated during this stage. During the draining of the coating off the object, a variation of film thickness occurs. Generally it has been found that, the coating thickness at the top of the substrate is lower than at the bottom. For minimizing the variation of film thickness, care must be taken in selecting solvents for dip coating. Change in viscosity of coating results in change in film thickness. Consistent results can be achieved by keeping the viscosity of the coating constant. But to keep the viscosity constant is difficult due to the volatility of the solvent. Hence 
to achieve constant viscosity of coating solvent must be added to replace the solvent lost from coating reservoir. Viscosity can be increased not only due to the evaporation of solvent but also by the chemical reaction of the coating components [23]. If some crosslinking reactions occur in the coating bath, viscosity increases. The extent of such reactions of the coating components must be minimal. The crosslinking reactions between the metallo-organic compounds can be slowed down by addition of a chelating or complexing agent like acetyl acetone (acac), ethyl aceto acetate (EAA), acetic acid, methacrylic acid etc [24, 25].

\subsection{Effect of Atmosphere}

In dip-coating process the evaporation of the solvent is affected by various atmospheric condition. The evaporation of the solvent causes destabilization of the sol, which results in a gel formation process. Because of this gelation process, particles of small sizes are formed in the sol (in nanometer range) and a transparent film is formed. This resulting transparent film should be densified by thermal treatment at well-defined densification temperature, which is often decided by the composition of the sol. In the following figures as mentioned in Figure 4, the sequential steps of dip coating process and the gelation process have been depicted.

\subsection{Other Controlling Factors}

Several other factors may be responsible for the deviation from the predicted results in various $\mathrm{pH}$ and viscosity regions. Equation (1) and (2) have been derived by assuming the Newtonian viscosity and any other effects of evaporation have been ignored. However due to evaporation of the solvent, the concentration of the sol increases progressively, which leads to increase in the viscosity of the sol. As a consequence, a stiff network will be formed having nonNewtonian behavior and one can get difference between the theoretical and experimental results [26,27]. In sol-gel film deposition, evaporation generally solidifies the coating. The most important factor is rate of diffusion of the vapor from the film [21], which in turn is dependent on the movement of the gas within a very thin layer $(\sim 1 \mathrm{~mm})$. The rate of evaporation is expressed in terms of empirical mass transfer coefficient, $\mathrm{k}$, according to

$m=k(p c-p i)$

where, $p_{c}$ is the partial pressure of the volatile substance in equilibrium with the surface and $p_{i}$ is the partial pressure at a distance I away. During dip coating, the substrate speed can strongly affect the evaporation rate. But practically, $\mathrm{k}$ and $(p c-p i)$ are strongly influenced by the uncontrolled current above the bath $[21,28]$.

The composition of the liquid bath is generally unaffected by evaporation rate. But greater the substrate speed, thinner will be the film. As a consequence, much thinner film will experience an increase in concentration; so greater will be the overlap of the deposition and drying stage. According to Scriven [20] the overlap of the deposition and drying stages may cause a flow driven by a gradient in surface tension, which is also referred as Marangoni effect [29]. This phenomenon results from differential evaporation of the more volatile component causing a potential gradient in the surface tension. Other factors that may influence the expected results are Van der waals forces [30] and capillary pressure [31].

\subsection{Advantage and Disadvantage}

Advantages: Most of the industries are using dipping process for the coating as it is convenient for fast production, cost effective, more uniform coating as coating is completely penetrated and off course, does not need adequate skilled operator and experience.

Disadvantages: Sometimes the following observations are noticed while processing the strip through the dipping vessel. The observations are; it is difficult to obtain uniform coating thickness as coating thickness is very sensitive towards the viscosity of the solution and withdrawal speed.

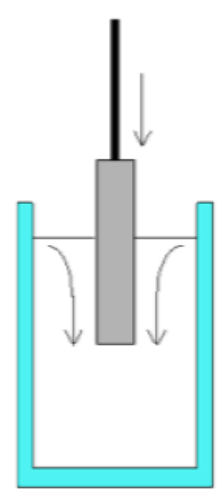

dipping

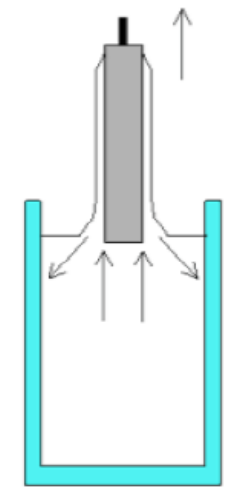

wet layer formation

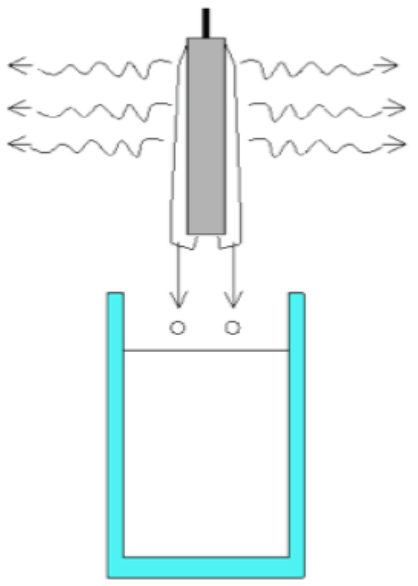

solvent evaporation

Figure 4: Sequential steps in a dip coating process [25]. 


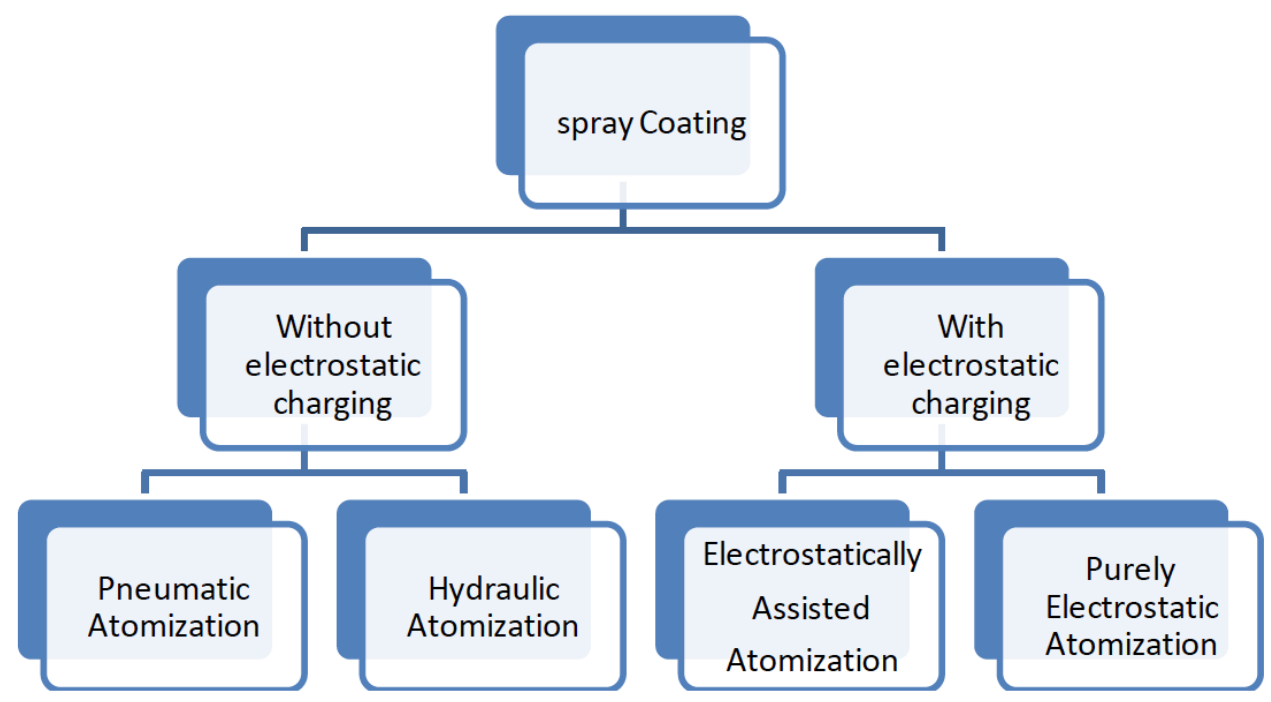

\section{SPRAY COATING}

Spray coating technique is widely used in industry for coating the irregularly shaped substrates like lamp or container glass, pressed glass parts etc. but spray technique offers several advantages over dip coating technique, such as, the processing speed is almost ten times faster than that of dip coating method, the waste of coating sol is much smaller. Atomization process consists of breakup bulk liquids into drops into fine droplets [32]. On the basis of the substrate to be coated and technological requirements, a number of atomization methods are available in recent time, by which it is possible to achieve excellent coating quality and reproducibility. The methods can be mainly categorized as follows [8].

\subsection{Atomization without Electrostatic Charging}

The mechanical force alone achieves atomization of coating without electrostatic charging. However this process is greatly dependent on the speed of the air jets, of combination of rapid coating flow and air jets and arising speed from centrifugal forces [8].

\subsubsection{Pneumatic Atomization (Compressed Air Spray)}

In this method the coating liquid is supplied through the coating nozzle and is controlled by injector, the compressed air required for the atomization is released by the trigger guard and then emerges from the air circuit and entrains the coating from the coating nozzle. After this, atomization of the coating takes place by extremely rapid air jet, depending on exchange of impulse between air and coating [8]. Compressed air guns are one of the most important tools and are widely used for following advantages (1) very fine atomization and good surface quality can be achieved, (2) uniform coating thickness and almost defect free surface is achievable and (3) wettability is enhanced by air pressure.

However, with good atomization capacity, the method is also not free from the following disadvantages such as material losses due to overspray, risk of surface defects due to spray mist and adequate skill is required for this operation.

\subsubsection{Hydraulic Atomization}

In airless hydraulic atomization method a very high pressure of about 200-400 bar is applied on the coating material, through a fine nozzle. The high speed and turbulences cause the jet of coating material to be torn apart and atomized immediately after leaving the nozzle [8, 31, 32].

By air assistant hydraulic atomization the droplets are achieved with greater uniformity and with same particle size. A lower coating pressure (approx. $60 \mathrm{bar}$ ) is required for the atomization [31, 32].

There are low spray mist formation which is leading to less overspray and high material yield as an advantage of this method. Operational skill set is less as compared to pneumatic method is noticed.

Some mentionable disadvantages are inferior atomization process, coating quantity cannot be controlled during application and water borne coating cannot be deposited by this technique as there is a possibility of dispersion damage by high shear. This process causes extremely noise at shop floor and expensive plant is required.

\subsection{Atomization with Electrostatic Charging}

The energy required for spray application of coating materials can also be electrical. If charged liquid particles with the charge $Q$ are brought in the contact of an electrical field of strength $E$, a force $F_{1}$ acts on them. As a result, the material is attracted by the electrode of opposite charge [32-34].

$F_{1}=Q \cdot E$

The electrical force is directly proportional to the charge of the liquid and the electrical field strength. Because the frictional force $F_{2}$ acts in the opposite direction 
$\mathrm{F}_{2}=6 . \pi . \eta \cdot r . u$

$\eta=$ dynamic viscosity

$r=$ radius of the nozzle

a stationary state is soon established according to the Stoke's Law. The electrically charged particles achieve a speed $u$ and moves along the field line.

$u=\frac{Q \cdot E}{6 \cdot \pi \cdot \eta \cdot r}$

In spray coating process, the spray equipment transfers the electrical charge to the liquid for droplet formation and the transport to the counter electrode. A sufficiently strong electric field has to be generated by connecting a direct voltage between the atomizer and the object to be painted. Hence, the whole process of electrostatic paint application can be divided into the following steps:

- $\quad$ Generation of an electrical field

- $\quad$ Charging of the coating material

- $\quad$ Formation of paint droplets

- The transport to the object and discharging of the film

\subsubsection{Purely Electrostatic Atomization}

In pure electrostatic atomization technique electrical energy is applied to liquid coating at nozzle tip and the liquid column is broken down into fine droplets. The charge transfers to the fluid and the repulsive force between the atomizer and the fluid triggers off the droplets and the droplets are directed from the atomizer to the substrate to be coated. One of the important factors in electrostatic atomization method is the electrical conductivity of the coating material, which can be adjusted by the appropriate choice of solvent and additive, according to the requirement $[8,32,35,36]$.

\subsubsection{Electrostatically Assisted Atomization (Pneumatic and Hydraulic Application)}

Depending on the paint two different types of charging process have been found to be effective. Internal charging takes place either before atomization or after exiting the spray head (after the completion of droplet formation) by external charging. In the case of pneumatic application internal charging process is used. The coating material passes a high voltage electrode in an electrically insulated gun and receives the electrical charge as shown in Figure 5. Since the droplets that are formed already carry a charge, the surface tension is reduced due to the repelling electrical forces and a better atomization takes place. But internal charging is only possible when the coating material possesses a specific resistance in the range of $10^{6}-10^{10} \Omega$ $\mathrm{cm}$. This internal charging can be carried out with a higher spray viscosity, lower spraying air pressure and lower emission. However the external charging method results in material loss due to overspray [8, 22, 32].
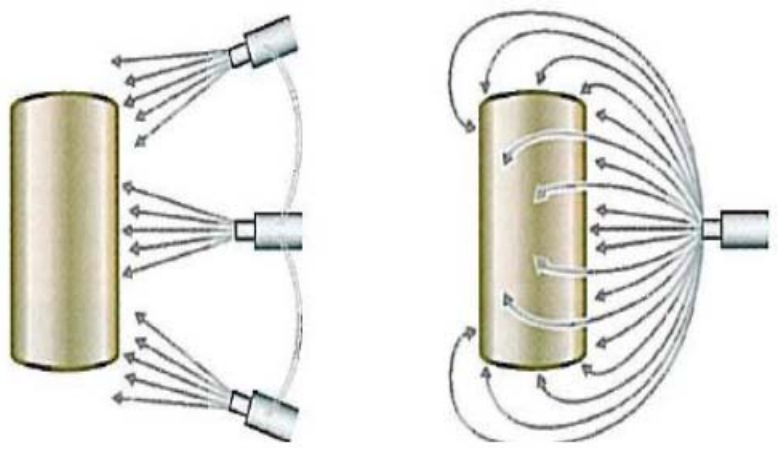

Figure 5: With ordinary spray guns (left) coating should be sprayed from different angles but with electrostatic spray guns (right) coating is adhered to a wide area from a single spray direction [22].

Electrostatic atomization technique provides good coating yield and almost $100 \%$ application efficiency at a reasonable throwing power. There are no wear on spraying edges due to reduction in mechanical stress. The limitations of this process are low flow rate of coating and risks of excess coating at edges.

\subsection{Factors Affecting the Spray Coating}

\subsubsection{Discharge Speed}

Droplet formation by liquids after discharge from nozzles is affected by the speed relative to the air. If a liquid is discharged very slowly out of nozzle a continuous line of liquid is initially formed which is then constricted after a minimum length is reached, before attaining a thermodynamically stable state of dripping. A further increase in discharge speed results oscillation in the line of the liquid. This oscillation is produced due to the friction between the liquid droplets with the ambient air. Under this condition, the droplets are formed by splittering. If the discharge velocity is further increased, the air friction is also increased and the line of liquid is converted into transverse waves. With even greater pressure, the primary droplets collide with significantly slower air and the dynamic pressure of air deforms the primary droplets. This deformation of the primary droplets causes secondary atomization and relatively smaller droplets are formed [32, 37]. When the liquid coating is breakup into droplets by the application of extremely high air pressure or fluid pressure, "Overspray" may occur. Higher the pressure, higher is the forward velocity of air. Some of the droplets approach the surface to be coated and bounce back by eddy current of air. This phenomenon is known as "Overspray". For minimizing this effect, spray pressure should be adjusted to an optimum value [22, 38, 39].

\subsubsection{Rheology of Coating Solution}

Surface Tension: Surface tension tends to stabilize a liquid and the breakup of liquid into smaller droplets is prevented. Everything else being equal liquid having higher surface tension will tend to have larger average droplet size,

Viscosity: Viscosity of a fluid resists its agitation and will impart similar influence on droplet size as surface tension. A 
more viscous coating solution will breakup into larger droplet size upon atomization.

Density: Density causes a fluid to resist acceleration. Similar to surface tension and viscosity, higher density of coating fluid will result in the formation of larger droplet size [33, 40].

\subsubsection{Distance between Spray Gun and the Substrate}

The average time of the droplet flow and thus the solvent content of the resulting film is influenced significantly by the distance of the gun to the substrate to be coated. If the distance is short, it results in wet and low viscous paint droplets. On the other hand, with a relatively greater distance, the droplets become too dry because they are in motion for a longer period [22, 32]. Some droplets may fall out of the spray pattern under the force of gravity. Larger the spray pattern and distance between the spray gun and the surface to be sprayed, higher will be the fall out rate. This distance also has a very important role in balancing solvent evaporation rate with the particular spray equipment and procedure. Higher distance from the spray gun orifice to the substrate, greater will be loss of solvent due to evaporation. Coatings are formulated best on the substrate at a specific distance between the gun and the surface. This distance should kept as constant as possible throughout the spraying operation [32]. In practice the spray gun is kept at distance of 25-30 cm away from the object for achieving best compromise between the evaporation properties and the rising amount of overspray with increasing distance [32, 41].

\subsubsection{Mathematical Equations Relating the Liquid Flow and the Variables Affecting the Flow}

The droplet size is a function of nozzle width and the coating rheology such as surface tension, viscosity and density. The variables which characterizes the flow such as density, flow rate, viscosity and surface tension can be merged together to form dimensionless number. The numbers are the Reynolds Number (Re), the Webers Number (We) and Ohnesorge Number (Ohz).

$$
\begin{aligned}
& \operatorname{Re}=\frac{u \cdot d \cdot \rho}{\eta} \\
& W \mathrm{e}=\frac{u^{2} \cdot d \cdot \rho}{\sigma} \\
& O h z=\frac{\sqrt{W e}}{\operatorname{Re}}
\end{aligned}
$$

Where, $u$ is the discharge velocity, $d$ is the nozzle diameter, $\rho$ is the density of the coating solution, $\eta$ is the dynamic viscosity of the coating solution and $\sigma$ is the surface tension of the liquid.

In the absence of any other influencing variables the droplet size can be calculated. There are various references in literature for calculating the droplet size. Among the various methods the Walzel's method provides a simple and straightforward formula for calculating the droplet size and is as follows

$$
d_{32}=51 \cdot \operatorname{Re}^{-0.39} \cdot W e^{-0.18}\left[\frac{m \text { coating }}{m \text { air }}\right]^{0.29} \cdot d_{D}
$$

$\mathrm{d}_{32}$ is the mean droplet size. The Reynolds number and Weber number contain relative speed of air and the variables affecting the liquid flow such as density, surface tension and viscosity. These variables are supplemented by the ratios of flow rates $m$ coating and $m$ air and the nozzle diameter $d_{D}$ [32].

\subsubsection{Effect Of Spray Parameters And Coating Characteristics On Final Coating [22, 32]}

In Figure 6 the influence of various coating properties like viscosity, surface tension, density and flow rate of coating on the droplet size distribution during pneumatic atomization has been shown schematically.

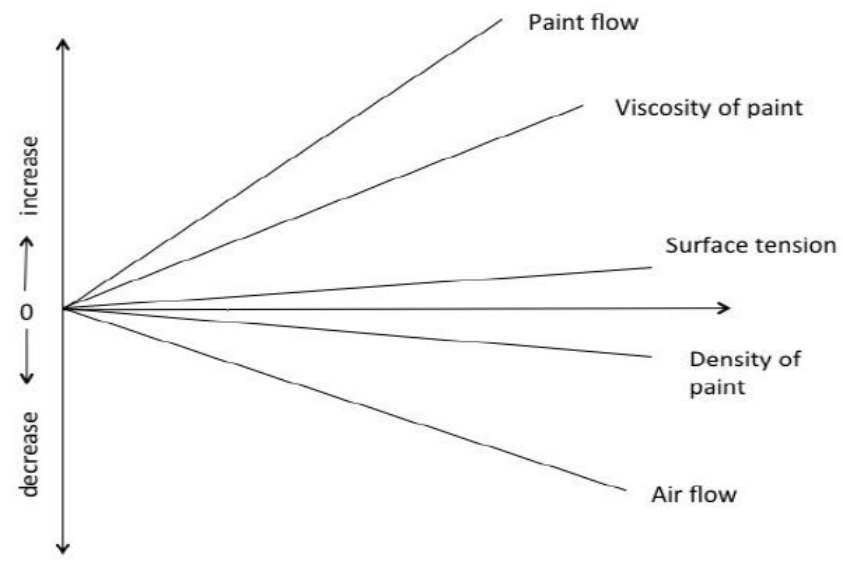

Figure 6: Influences on droplet size distribution during pneumatic atomization [8, 31].

\section{ROLL COATING}

The roll coating system is used to deposit liquid layers on continuous moving objects. This application method is mainly used for flat or cylindrical surfaces [22]. Continuous, largescale application is possible if appropriate equipment and coating supply systems are used [32]. Relatively slow evaporating solvents must be used to avoid viscosity build up on the rolls of the coater. The pot life of the coating must be long enough, since the rate of turnover of coating through the system is relatively lower [22]. There are many types of roll coating procedures such as two-roll coater, three-roll coater, forward roll coater and reverse roll coater.

\subsection{Two-Roll Coater \& Three-Roll Coater}

The planer objects to be coated is first transported underneath the fixed transfer roll by a conveyor. The coating material is first taken from the storage by a rotating dispensing roll, known as the 'pick-up roll'. The coating is then transferred from pick up roll to the applicator roll, which 
Table 6: Effect of Change in Spray Parameter and Coating Characteristics on Final Coating Properties [8]

\begin{tabular}{|c|c|}
\hline Change in Spray Parameter and Coating Characteristic & Overspray proportion is changed from large to small \\
\hline \hline If nozzle diameter is changed from large to small & Surface quality is changed from poor to excellent \\
Average particle size is changed from large to small & Coating speed is changed from high to low \\
Coating viscosity is changed from high to low & \\
if spraying air pressure is changed from low to high &
\end{tabular}

Table 7: Fluid Properties Affecting the Spray [33]

\begin{tabular}{|c|c|c|}
\hline Fluid Property & Liquid Droplet Size & Reason \\
\hline \hline Viscosity increases & Increases & Tesists agitation of the fluid and tends to prevent its breakup \\
\hline Surface tension increases & Increases & Higher pressure results small droplets \\
\hline Pressure increases & Decreases & Trid and prevents its breakup into smaller droplets \\
\hline
\end{tabular}

is also rotating. This applicator roll transfers the coating material to the moving object to be coated. Roll coater consists of pick-up roll and applicator roll are commonly referred as two roll coater shown in Figure 7 (left). However to provide better conditions to ensure a smooth film three roll system is used. All the three roll systems have a metering roll in between the pick-up roll and applicator roll as shown in Figure 7 (right). Each roll is driven individually and their speeds can be regulated independently [32].

\subsection{Forward Roll Coating \& Reverse Roll Coating}

If the applicator roll turns in the same direction as the conveyor then it is known as forward roll coating or direct roll coating but if it turns in the opposite direction of the conveyor then it is termed as reverse roll coating as shown in Figure 8. One of the major drawbacks of forward roll coating is incomplete and uneven transfer of the coating onto the substrate because of the film splitting phenomenon. Film splitting always produces almost a non-uniform, visually distorted coating that is known as ribbing defect. Ribbing is a commonly used term describing the nonuniform coating condition consisting of somewhat regularly spaced concentric ridges of heavier coating on the coating roller.

However by the reverse roll coating process efficient and accurate transfer of coating on the substrate is secured. A

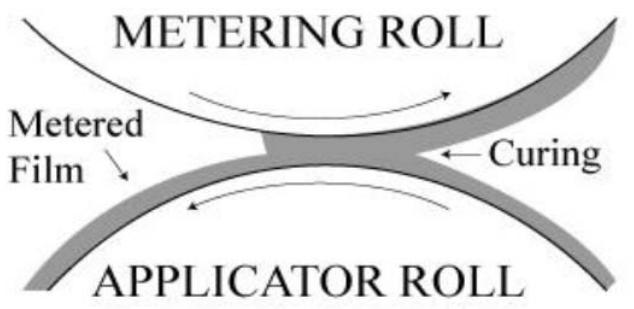

Figure 7: Picture of a two rolls coater (left) \& three rolls coater (right) [41]. wide variety of film thickness (from 3 to $100 \mu \mathrm{m}$ ) can be achieved and the coating solution with higher viscosity can be deposited on the work piece. Hence unlikethe forward roll coating, high-gloss, texture free and uniform surface can be obtained with reverse roll coating method [8]. The reverse metering action of a reverse roll coater provides a smoother, more uniform metered film by avoiding the film split pattern and the ribbing phenomenon.

\subsection{Rheological Properties of Solvent for Roll Coating}

For roll coating technique the solvent must have slow evaporation rate to avoid viscosity buildup on the rolls of the coater. To minimize the solvent loss on the rolls and to keep the viscosity low the coating should be formulated properly so that it exhibits a Newtonian flow. If the coating possesses thixotropy, the rate of the recovery of the low shear viscosity should be as slow as possible [22]. Apart from having very low evaporation rate, the solvent must have very good solvent power for film forming agents. As well as the rubberized transfer roll should not be swelled when comes in contact with the solvent. Practically it has been found that, rolls of butyl rubber and solvents such as methyl glycol acetate, butyl glycol acetate or butyl diglycol acetate give very satisfactory results [32, 42].

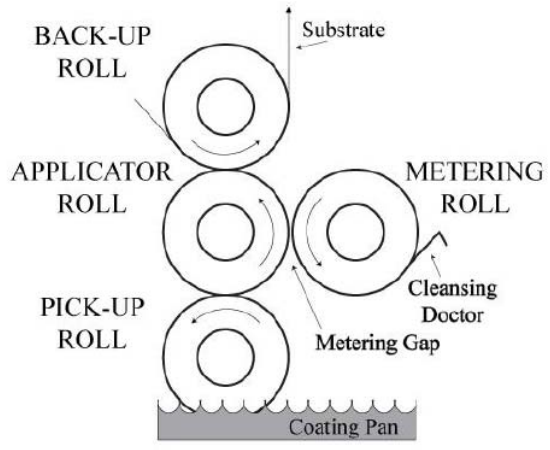



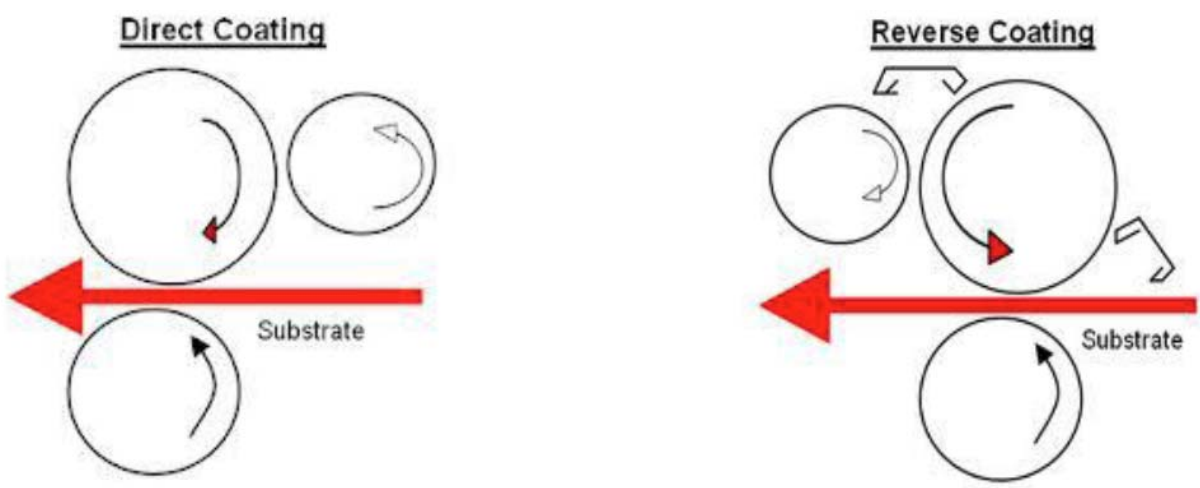

Figure 8: (a) Schematic of forward roll coating (left), (b) reverse rollscoating (right) [41].

\section{CHEMICAL VAPOR DEPOSITION}

Chemical vapor deposition is one of the mostly used techniques for material processing. The major application of this method is thin film coating on the substrate. In simple words, it can be said that CVD process involves flowing of precursor gas or gases into a chamber containing the heated substrate to be coated [44]. A chemical reaction takes place near or on the hot substrate surface followed by the deposition of the thin film on the surface to be coated. The chemical by product, that is produced during the thin film deposition method and the unreacted precursor molecules are exhausted out of the chamber. A large variety of precursor molecules can be deposited as thin film by CVD process, such as, metal halide, metal-halo-hydrides, metal hydrides, metal-organic compounds, organometallic compounds etc. The metal-organic compounds have got some advantages over the metal hydrides and metal halides e.g. the metalorganic compounds need lower reaction and deposition temperature and are less toxic then metal halide or metal hydride [44-46].

\subsection{Processes, Principle and Deposition Mechanism}

A CVD process is composed of the following fundamental steps [47]:

\subsubsection{Production of Gaseous Reactive Precursors}

In this step, precursor vapor is generated and then directed towards the reactor. Depending on the nature of the precursor (whether, gaseous, liquid or solid) the reactor is constructed. The sublimation of the solid precursor depends upon the surface area of the solid and contact time. A bubbler is often used to vaporize the liquid precursor. Flash evaporation method is also employed to vaporize the liquid precursors. The liquid precursor is metered with the help of a syringe pump into the flash evaporator, when the liquid substance is vaporized instantaneously.

\subsubsection{Transport of the Gaseous Precursors to the Reaction Chamber}

In this step the precursor vapor is moved to the reaction chamber. Generally a carrier gas is used carry on the vapor to the reactor. A reactive gas such as $\mathrm{H}_{2}$ or inert gases like argon, neon are used to carry the vaporized reactant into the reaction chamber. The pressure over the source, the source temperature and the flow rate of the carrier gas control the flow rate of the reactant. The gaseous reactant and the carrier gases remain in almost $99.9999 \%$ pure state during the transport. They are carried towards the reactor from highpressure gas cylinder. To eliminate the possibility of contamination, the gases are often purified further to remove even small traces of oxygen or moisture.

\subsubsection{Vaporized Reactant Undergoes Gas Phase Reaction to Form Intermediate Species}

The vaporized intermediate species can undergo homogeneous gas phase reaction above deposition temperature, resulting in the formation of powders and volatile by products. The powder are collected on the substrate surface, whereas, the gaseous by products are exhausted out of the deposition chamber. On the other hand, if this gas phase reaction takes place below the deposition temperature, then this intermediate species forms a thin layer near the substrate surface [48-51].

Adsorption of the gaseous substance onto the heated substrate and a heterogeneous reaction takes place at gassolid interface accompanied by the production of deposits and gaseous by products.

\subsection{Criteria of A Suitable Chemical Precursor}

The chemical precursor for coating application through CVD process must have possess stability at room temperature, low vaporization temperature and high saturation vapor pressure. The vapor should be stable at room temperature before it undergoes decomposition or chemical reaction at higher temperature. It should be low toxicity, inflammability, explosively and inflammability as the desirable characteristics for large scale industrial application. Most of the metalorganic compound provides aforementioned criteria. This factor has fueled the usage of the metal-organic compounds as protective coating. The CVD technique leads to a mean of obtaining thin film by using pre-selective low cost precursor as the starting material for the deposition, and precursors are readily available in highly purified form [52-55]. 


\subsection{Various Process Parameters Controlling the Film Deposition}

\subsubsection{Deposition Temperature}

The deposition temperature at which the film is deposited is very important parameter as it controls the thermodynamics and kinetics of the coating process. The deposition temperature must be controlled in such a way so that, the reaction takes place strictly on the substrate only and not in the gas phase. A minor change in the temperature may change the reaction kinetics and may result in inferior coating $[44,56]$

\subsubsection{Atmospheric Pressure}

CVD process is carried in the range of atmospheric pressure to high vacuum. At atmospheric pressure the growth process is transport controlled. To eliminate the high sensitivity of the growth process and film composition on the pressure, CVD process is carried out at a pressure lower than $\sim 1 \mathrm{~atm}$. The total pressure inside the reactor and the pressure of the reactants and products should be controlled appropriately to obtain a film having uniform thickness and good adhesion [45].

\subsubsection{Coating Uniformity}

Non-uniformity in the resulting coating may arise from the depletion of the precursors. This problem can be avoided by i) rotating the substrate and ii) mixing the precursors properly by stirring or reversing the gas flow direction $[45,56,57]$.

\subsubsection{Coating Substrate Adhesion}

The adhesion of the coating on the substrate can be improved by i) eliminating all type of substrate contamination such as inherent oxide layer due to oxidation of the substrate, ii) the attack of unused precursors or chemical by products forming stable but weakly bonded compounds on the substrate coating surface, iii) depletion of gaseous precursors creating a difference in gas composition [58-62].

\subsection{Advantages and Disadvantage of CVD Process}

Although CVD process is a very complex process, but due the following advantages the process is being considered as one of the widely used and highly sophisticated techniques for the thin film formations. For this reason this method has been extensively studied and well documented [45, 63-70]. Coating with highly dense and pure materials is obtainable. The thin film with excellent adhesion and good reproducibility is possible with high deposition rates. It is also possible to coat uniformly the complex shaped objects as CVD is a nonline-of-sight process. This coating process is also have certain limitations such as use of toxic, corrosive, flammable precursor gases can cause some chemical or safety hazards and difficult to deposit multicomponent materials with well defined stoichiometry as different chemical precursors have different rates of evaporation.

\section{FLOW COATING}

In the flow coating technique the liquid coating system is poured on substrate to be coated. In this method the substrate is inclined at an angle about $40^{\circ}$ to $50^{\circ}$ with the vertical in front of the operator. The coating thickness depends on the inclination angle of the substrate, the coating liquid viscosity and evaporation rate. As a variation of this process, spinning of the substrate may be required in order to

Table 8: An Overview of Methods of Application

\begin{tabular}{|c|c|c|c|c|c|}
\hline $\begin{array}{l}\text { Method of } \\
\text { Application }\end{array}$ & Surface Quality & $\begin{array}{l}\text { Restriction in } \\
\text { Surface } \\
\text { Dimension }\end{array}$ & $\begin{array}{l}\text { Operating } \\
\text { Speed }\end{array}$ & $\begin{array}{l}\text { Application } \\
\text { Efficiency }\end{array}$ & Application Area \\
\hline Brushing & $\begin{array}{l}\text { Moderate to } \\
\text { good }\end{array}$ & Small areas & Very low & Very good & Long wearing protective coating for metal sheets \\
\hline Rolling & Good & Small areas & Moderate & Very good & $\begin{array}{l}\text { In steel industries for high temperature annealing } \\
\text { process, in paper industry for the formation of the } \\
\text { paper from wet pulp }\end{array}$ \\
\hline Dip coating & $\begin{array}{l}\text { Moderate to } \\
\text { good }\end{array}$ & Small areas & High & Very good & $\begin{array}{l}\text { Anti corrosive coating for steel sheets, detector, } \\
\text { sensors, antireflection coating, ceramic protective } \\
\text { coating }\end{array}$ \\
\hline Spin coating & Good & Small areas & High & Low & Magnetic devices, solar cell devices, CD, DVD ROM \\
\hline Spray coating & Good & - & Moderate & Good & $\begin{array}{l}\text { Automotive, decorative, marine, abrasion and } \\
\text { corrosion resistance purpose, photoconductor coating }\end{array}$ \\
\hline Flow coating & Moderate & $\begin{array}{l}\text { Restricted working } \\
\text { width }\end{array}$ & $\begin{array}{l}\text { Very good } \\
\text { high }\end{array}$ & High & $\begin{array}{l}\text { Industrial liquid coating to cover multi dimensional } \\
\text { surfaces of carbon steel, aluminum, pipeline coating, } \\
\text { wood coating, }\end{array}$ \\
\hline CVD & Good & - & Very good & - & $\begin{array}{l}\text { Semiconductors, dielectric and metallic films, optical } \\
\text { fibers, }\end{array}$ \\
\hline Roll coating & $\begin{array}{l}\text { Moderate to very } \\
\text { good }\end{array}$ & $\begin{array}{l}\text { Restricted working } \\
\text { width }\end{array}$ & Very good & High & $\begin{array}{l}\text { Wood panels, hard board, plastic foils, cardboard, } \\
\text { paper or metal coils }\end{array}$ \\
\hline Curtain coating & Very good & $\begin{array}{l}\text { Restricted working } \\
\text { width }\end{array}$ & High & Very good & Wall panel, metal doors, cupboards etc. \\
\hline
\end{tabular}


achieve more uniform and homogeneous film. If no spinning is applied, the film thickness can be changed from top to bottom of the substrate $[8,31]$.

\section{CURTAIN COATING}

Curtain coating is specially used to coat plane surfaces. The coating is applied by transporting the work piece on a conveyor belt through curtain of coating material flowing from a narrow adjustable slit. Adjusting the width of the slit and throughput rate of the object the thickness of the coating film can be controlled. Film thickness achieved by curtain coating comes in the range of 20 to $500 \mu \mathrm{m}$. Curtain coating can produce very good surface quality and almost $100 \%$ yield but it is only applicable for planer or slightly convex surfaces [8].

\section{AN OVERVIEW OF THE METHODS OF APPLICATION}

In the following section a concise overview of different application methods, their different criteria, application areas have been summarized in a tabular form:-

\section{CONCLUSION}

This review has thrown a light on current and potential application techniques to fabricate thin film by sol-gel process. The effect of variation of different process parameters on final sol-gel film composition has been described. The information in this review will help to identify, how all the different parameters should be controlled appropriately in order to obtain a final film with good coverage, uniform thickness, good adhesion and free of any defects such as cracks, pores, blisters etc. The selection of coating process should be done according to the final requirements of application and hence, the advantages and disadvantages of each technique should be judged carefully. However, a mention-worthy fact regarding this article is that, apart from the application techniques mentioned in this review, there are various sophisticated and potential application methods are available for thin film deposition. But this review has confined its discussion to the processes, which are applicable and suitable for sol-gel thin film deposition only.

\section{REFERENCES}

[1] Uhlmann DR, Suratwala D, Davidson K, Boulton JM, Tewoee G. Solgel derived coating on glass. J Non Cryst Solid 1997; 218: 113-22. http://dx.doi.org/10.1016/S0022-3093(97)00162-2

[2] Guglielmi M. Sol-Gel coatings on metal. J Sol Gel Sci Technol 1997; 8: 443-49. http://dx.doi.org/10.1007/BF02436880

[3] Sakka S, Woko T. Chemistry: Spectroscopy and Application of sol-gel glasses. Ed. Reisfield R, Spring-Verlag, 1992; 89.

[4] Attia SM, Wang J, Wu G, Shen J, Ma J. Review on sol-gel and optical applications. J Mater Sci 2002; 18: 211-18.

[5] Homberg K, Matthews A. Coatings Tribology: Properties, Mechanisms, Techniques and Applications In Surface Engineering, First edition, Elsvier, 1994

[6] Singh V. Thin film technology: An introduction to deposition technique and overview, [cited on 11Jan, 2016] available from
http://www.itmindia.edu/images/ITM/pdf/Thin\%20Film\%20Technology $\% 20 \mathrm{An} \% 20$ Introduction\%20to\%20Deposition.pdf

[7] Friz M, Waibel F. Coating Materials. cited on [Jan 11,2016] available from http://www.thinfilmproducts.umicore.com/Library/LibraryArchive/ show_article_coating_materials_12june03.pdf

[8] Brock T, Groteklaes M, Mischke P. European Coatings Handbook, Vincentz Verlag, Hannover, Germany 2000.

[9] Spin Coat Theory [cited on Dec 10, 2016] available from http://www.clean.cise.columbia.edu/process/spintheory.pdf

[10] Sahu N, Parija B, Panigrahi S. Fundamental understanding and modeling of spin coating process: A review. Indian J Phys 2009; 83 : 493-502.

http://dx.doi.org/10.1007/s12648-009-0009-z

[11] Meyerhofer D. Characteristics of. resist films produced by spinning. J Appl Phys 1978; 49: 3993-3997. http://dx.doi.org/10.1063/1.325357

[12] Middleman S. An Introduction to Fluid Dynamics, John Wiley and Son, New York 1998.

[13] Omar O, Ray AK, Hassan AK, Davi F. Resorcinol calixarenes (resorcarenes). Supramolecular Science 1997; 4: 417-421. http://dx.doi.org/10.1016/S0968-5677(97)00024-2

[14] Emsile AG, Bonner FT, Peck LG. J Appl Phys 1958; 29: 858-62. http://dx.doi.org/10.1063/1.1723300

[15] Matuso S. Handbook of thin film deposition and techniques, Noyes, Park Ridge, NJ, 1982.

[16] Advances in Sol-Gel Technology [cited on Jan 11, 2016], available from http://www.ceramicindustry.com/articles/83256-advances-in-solgel-technology

[17] Brinker CJ, Frye GC, Hurd AJ, Ashley CS. Fundamentals of Sol-Gel Dip Coating. Thin Solid Films 1997; 201: 97-108. http://dx.doi.org/10.1016/0040-6090(91)90158-T

[18] Brinker CJ, Keefer KD, Schaefer DW, Assink RA, Kay BD, Ashley CS Sol-gel transitions in simple silicates II. J Non-Cryst Solids 1984; 63 : 45- 59. http://dx.doi.org/10.1016/0022-3093(84)90385-5

[19] Scriven LE, Brinker CJ, Clark DE, Ulrich DR, Eds. Better Ceramics Through ChemistryllI. Mat. Res. Soc, Pittsburgh, PA, 1988; 717-29.

[20] Yusuf OB. Improved non linear solution of dip coating flow, [cited on Jan 9,2016], available from http://ir.lib.uwo.ca/cgi/viewcontent.cgi? article $=2087 \&$ context $=$ etd

[21] Landau LD, Lecich BG. Dragging of a liquid by a moving plate. Acta Physiochim URRS 1974; 17: 42-54.

[22] Wicks ZW, Jones FN, Pappas SP, Wicks DA. Organic Coatings: Science and Technology, Third Ed., John Wiley \& Sons Inc, USA 2007. http://dx.doi.org/10.1002/047007907X

[23] Bera S, Udayabhanu G, Narayan R, Rout TK. Sol-Gel Process for Anti Corrosion Coating. Journal of Research Updates in Polymer Science 2013; 2: 209-31.

[24] Corrosion inhibiting sol gel coatings for metal alloys US Patent 6579472

[25] Schmidt H, Mennig M. Wet Coating Technologies for Glass available from [cited on Dec, 23] available from http://www.solgel.com/articles/ Nov00/mennig.htm

[26] Brinker CJ, Scherer GW. Sol-Gel Science: The Physics and Chemistry of Sol-Gel Processing, Academic Press Inc., New York, 1990.

[27] Jackson JD. Classical Electrodynamics, Second Ed. Wiley, New York 1979.

[28] Adamson AW. Physical Chemistry of Surfaces, Fourth Ed. Wiley. New York, 1982.

[29] Brinker CJ, Clark DE, Ulrich DR. Better Ceramics Through Chemistry III, Mat. Res. Soc, Pittsburgh, PA, 1988; 731-742.

[30] Gennes PG, Wetting: Statistics and Dynamics. Rev Mod Phys 1985 57: 827-63

http://dx.doi.org/10.1103/RevModPhys.57.827

[31] Goldschmidt A, Strietberger HJ. BASF coating Handbook: Basics of Coating Technology, Second revised Edition, Vincetz, Germeny, 2007.

[32] Atomization-Elliot equipment [cited on Jan 11, 2016] available from http://www.elliottequipment.com/MediaLibraries/ElliottEquipment/PDF s/Ask\%20Elliott/ATOMIZ_1.PDF

[33] Lefebvre A. Atomisation and Sprays, Hemisphere Publishing, New York, 1989 


\section{Journal of Coating Science and Technology, 2016, Volume 3, No. 1}

[34] Mehrhardt MR. Dissertation, Berlin 1978

[35] Cloupeau M, Prunet-Foch B. Electrostatic Spraying of Liquids: Main Functioning Modes. J Electrost 1990; 25: 165-184. http://dx.doi.org/10.1016/0304-3886(90)90025-Q

[36] Brenn G, Domnik J, Lindenthal A, Kruger M. $8^{\text {th }}$ International Coating Process Science and Technology Symposium, New Orleans.

[37] Walzel P. Spraying and atomizing of liquids In. Dortmand TU Ullmann's Encyclopedia of Industrial Chemistry, Willey-VCH VerlagGmbh\& Co KgaA, Germany 2015.

[38] Reipschlager O. Dissertation Unipaderborn 2002

[39] Basic electrostatic spray finishing, cited on [Jan 11, 2016], available from http://www.hbparke.info/help_pages/electrostatics_321-028.pdf

[40] Satas D, Tracton AA. Coating Technology Handbook, Second Edition, Dekker M, New York 2001.

[41] Coating Application Methods [cited on Jan9, 2016] available from http://www.pcoatingsintl.com/wp-content/uploads/2014/05/ APPLICATION-METHODS-FOR-VUEGUARD-901-PRODUCTS.pdf

[42] Schoff CK. Rheology, Federation of societies for coating technology, Blue Bell, PA, 1991.

[43] Roll Coating Nameplates [cited on Jan9, 2016] available from http://www.norcorp.com/nameplate-blog/bid/26014/Roll-CoatingNameplates

[44] Creighton JR, Ho P. Introduction to Chemical Vapor Deposition [cited on Jan 2, 2016] available from https://tss.asminternational.org/ content/ASM/StoreFiles/ACFAA6E.pdf

[45] Choy KL. Chemical vapor deposition of coating. Prog Mater Sci 2007; 48: $57-170$.

http://dx.doi.org/10.1016/S0079-6425(01)00009-3

[46] De Lodyguine JS. Illuminant for incandecent lamps. US patent 5750021893.

[47] Choy KL. In: Nalwa HS, editor. Handbook of nanostructured materials and nanotechnology, vol. 1: synthesis and processing. San Diego (CA): Academic Press 2000

[48] Dai H, Franklin N, Han J. Exploiting the properties of carbon nanotubes fornanolithography. Appl Phys Lett 1998; 73: 1508-10. http://dx.doi.org/10.1063/1.122188

[49] Li WZ, Xie SS, Qian LX, Chang BH, Zou BS, Zhou WY, et al. Large Scale Synthesis of Aligned Carbon Nanotubes. Science 1974; 1274: 1701-03.

[50] Kong J, Franklin NR, Zhou CW, Chapline MG, Peng S, Cho KJ, et al. Nanotube molecular wires as chemical sensors. Science 2000; 287 : 622-25.

http://dx.doi.org/10.1126/science.287.5453.622

[51] Nagy G, Levy M, Scarmozzino R, Osgood RM, Dai H, Smalley RE, et al. Erratum: "Carbon nanotube tipped atomic force microscopy for measurement of $<100 \mathrm{~nm}$ etch morphology on semiconductors. Appl Phys Lett 1998; 73: 529-31.

http://dx.doi.org/10.1063/1.122069
[52] Vescan L. Handbook of thin film process technology, Bristol (UK) 1995.

[53] Morosanu CE. Thin films by chemical vapor deposition. Amsterdam: Elsevier 1990.

[54] Sherman A. Chemical vapor deposition for microelectronics. Park Ridge (NJ): Noyes 1987.

[55] Vandelbucke L, In: Blocher JM, Ed. Proc 8th Int. Conf. on chemical vapour deposition. Princeton (NJ): Electrochemical Society 1981; $p$ 32.

[56] Hocking MG, Vasantasree V, Sidky PS. Metallic and ceramic coatings: production, high tem- perature properties and applications. Longman: Essex (UK) and John Wiley \& Sons: New York 1989.

[57] Hitchman ML, Jensen KF. Eds. CVD principles and applications. San Diego: Academic Press 1993.

[58] Jensen KF, Kern W. Thin film process II, Vossen JL, Kern W, Eds. Academic press, San Diego, CA 1991.

[59] Ohring M. The materials science of thin films, Academic Press, San Diego, CA, 1992.

[60] Nalwa HS. Handbook of Thin Film Materials, Vol I: Deposition and processing of thin films, Academic Press, San Diego, CA, 2002

[61] Glang R. Handbook of thin film technology, eds. Maissel LI, Glang R, McGraw-Hill, New York 1970.

[62] Adams AC. VLSI Technology, Second Edition, Sze SM, McGraw-Hill, New York 1988.

[63] Delhaes P. Proc. Fourteenth Conf. Chemical Vapor Deposition. Electrochem Proc Soc 1997; 486: 97-25.

[64] Cao G, Wang Y. Nanostructures and Nanomaterials: Synthesis, Properties and Applications, Second Edition, World Scientific Publishing Co. Pte. Ltd., Singapore 2011.

[65] Vaidyaraman S, Lackey WJ, Freeman GB, Agrawal PK, Langman MD. Fabrication of carbon-carbon composite by forced flow thermal gradient chemical vapor infiltration. J Mater Res 1995; 10: 1469-77. http://dx.doi.org/10.1557/JMR.1995.1469

[66] Abber RL. Handbook of Thin Film Deposition Processes and Techniques, ed. Schuegraf KK, New Jersey 1988.

[67] Hajjer JJ, Relif R, Adler D. Growth rate of polycrystalline silicon films deposited with and without plasma enhancement. J Electron Mate 1986; 15: 279-85.

http://dx.doi.org/10.1007/BF02659023

[68] Peirson HO. Handbook of chemical vapor deposition. Park Ridge (NJ): Noyes 1992.

[69] Shah IDA, Ed. Handbook of thin film process technology. Bristol (UK): Institute of Physics Publishing 1977.

[70] Levinson SB. Application of paints and coating, Federarion of societies for coatings technology, Blue Bell, PA, 1988 